\title{
NOVOS/VELHOS TEMPOS: DESAFIOS TÉCNICOS E POLÍTICOS PARA UMA NOVA GESTÃO
}

\author{
NUEVOS / VIEJOS TIEMPOS: DESAFÍOS TÉCNICOS $\Upsilon$ POLÍTICOS \\ PARA UNA NUEVA GESTIÓN \\ NEW / OLD TIMES: TECHNICAL AND POLITICAL CHALLENGES \\ FOR NEW MANAGEMENT
}

\author{
Benedito Medrado ${ }^{1}$, Simone Maria Hüning'2, \\ Anita Guazelli Bernardes ${ }^{3}$, Jorge Luiz Cardoso Lyra da Fonseca ${ }^{1}$, \\ Laura Vilela e Souza ${ }^{4}$, Lupicinio Iñíguez Rueda ${ }^{5}$, \\ Maria Lucia Chaves Lima ${ }^{6}$ e Mariana Prioli Cordeiro ${ }^{7}$ \\ ${ }^{1}$ Universidade Federal de Pernambuco, Recife/PE, Brasil \\ ${ }^{2}$ Universidade Federal de Alagoas, Maceió/AL, Brasil \\ ${ }^{3}$ Universidade Católica Dom Bosco, Campo Grande/MS, Brasil. \\ ${ }^{4}$ Universidade de São Paulo, Faculdade Medicina Ribeirão Preto, Ribeirão Preto/SP, Brasil. \\ ${ }^{5}$ Universitat Autònoma de Barcelona - UAB, Barcelona, Espanha \\ ${ }^{6}$ Universidade Federal do Pará, Programa de Pós-Graduação em Psicologia, Belém/PA, Brasil \\ ${ }^{7}$ Universidade de São Paulo, Departamento de Psicologia Social e do Trabalho, \\ Instituto de Psicologia, São Paulo/P, Brasil
}

Este editorial inaugura a Gestão 2020-2023 do novo corpo editorial da Revista Psicologia \& Sociedade.

Essa nova gestão é composta por quatro pesquisadores/as brasileiros/as (Anita Bernardes; Benedito Medrado; Laura Vilela e Souza e Simone M. Hüning) e um pesquisador estrangeiro (Lupicinio Iñíguez-Rueda) que integraram a coordenação editorial da revista Psicologia E̊ Sociedade na gestão do quadriênio anterior (1016-2019), além de uma pesquisadora que compôs a equipe editorial na referida gestão (Mariana Prioli Cordeiro), e dois novos/as editores/as com menor experiência em processos de gestão editorial, mas com grande identificação com princípios político-científicos da ABRAPSO e com experiências editoriais em consolidação, via participação em conselhos editoriais ou via produção de parecer ad hoc (Jorge Lyra e Maria Lucia Lima). Nessa composição, além da participação de pesquisador estrangeiro, garantimos a participação de pelo menos um/a pesquisador/a vinculado/a a instituições de quatro regiões do país.

Definimos como objetivo principal dar continuidade ao processo de consolidação e expansão da revista, fomentando a produção de conhecimento crítica, original, criativa e interdisciplinar, em consonância com os princípios ético-políticos que caracterizam a história da revista e da associação que ela representa. Em linhas gerais, o que aglutinou esse grupo foi a profunda identificação com os princípios ético-políticos da ABRAPSO e seu compromisso com a democratização do conhecimento e com leituras críticas sobre o fazer científico em psicologia social. 
Esta proposta se orienta a partir de um panorama de desafios tanto técnicos (onde se inclui a atualização da Plataforma Scielo) que, historicamente, tem tornado ainda mais complexa a editoração de periódicos científicos como também desafios de ordem político-acadêmica, dado o panorama atual da produção científica brasileira e as ameaças ao desenvolvimento de uma ciência crítica e emancipatória.

Para alicerçar nossas resistências contamos com a trajetória acadêmica e de pesquisa do grupo de editores/as, e em experiências prévias de colaboração mútua entre seus membros as quais atestam o compromisso político que esse corpo editorial tem demonstrado, de diferentes formas, com os modos de fazer política da ABRAPSO.

Vale ressaltar que a localização dos/as editores/as em diferentes regiões do país é considerada estratégica na medida em que afirma uma descentralização do corpo gestor da Revista, incorporando possibilidades de articulação das diferentes regiões como forma de fortalecimento da divulgação da Revista, e de aproximação com características dos modos e condições de produção de conhecimento nessas regiões.

Ressalta-se que a gestão local do periódico será acolhida pelos Programas de Pós-graduação em Psicologia da UFPE e da UFAL, dada a filiação institucional imediata do/a editor e editora chefe. Esse apoio envolve espaço físico e suporte institucional (laboratório e equipamentos) para as tarefas de editoração. O periódico conta, ainda, com apoio da UFSC, instituição de vínculo da editora gerente, e da UFPA, UCDB/MS, USP e UAB-Espanha (instituições de origem/as dos demais editores/as).

Esperamos continuar contando com a colaboração de todos e todas (autores/as, pareceristas, equipe editorial e especialmente leitores/as da P\&S) que consideram nossa revista um importante espaço para produção científica com postura crítica, autonomia intelectual e, obviamente, com qualidade técnica. Afinal, como nos ensina a pesquisadora feminista Patrícia Hill Colins, para desafiarmos as estruturas de poder a partir do seu interior, precisamos trabalhar sobre as rachaduras do sistema de produção científica e nos apropriar de forma flexível e crítica da linguagem que o sustenta.

\section{Referência}

Kind, L, Bernardes, A. G., Medrado, B., Souza, L. V., \& Hüning, S. M. (2016). Editorial. Psicologia \& Sociedade, 28(1), 1-2. https://doi.org/10.1590/1807-03102015v28n1p001 
BENEDITO MEDRADO

https://orcid.org/0000-0002-1085-5024

E-MAIL: beneditomedrado@gmail.com

SIMONE MARIA HUNING

https://orcid.org/0000-0001-8080-7733

E-MAIL: simone.huning@ip.ufal.br

ANITA GUAZELLI BERNARDES

https://orcid.org/0000-0003-4742-6036

E-MAIL: anitabernardes1909@gmail.com

JORGE LUIZ CARDOSO LYRA DA FONSECA

https://orcid.org/0000-0002-5381-2059

E-MAIL: jorglyra@gmail.com

LAURA VILELA E SOUZA

https://orcid.org/0000-0003-0732-8175

E-MAIL: laura.psisoc@gmail.com

LUPICINIO IÑÍGUEZ RUEDA

https://orcid.org/OOOO-0002-1936-9428

E-MAIL: lupicinio.iniguez@uab.es

MARIA LUCIA CHAVES LIMA

https://orcid.org/OOOO-0003-3062-2399

E-MAIL:marialuciacl@gmail.com

MARIANA PRIOLI CORDEIRO

https://orcid.org/0000-0002-5523-5099

E-MAIL: mpriolicordeiro@usp.br 